\title{
Blast Induced Damage to Surrounding Rock Mass in an Underground Excavation
}

\author{
Harsh Kumar Verma ${ }^{1}$, Narendra Kumar Samadhiya ${ }^{2}$, Mahendra Singh ${ }^{2}$ and Vilugundam Venkat Ramana Prasad ${ }^{1}$ \\ 1. CSIR-Central Institute of Mining and Fuel Research, Roorkee 247667, India \\ 2. Department of Civil Engineering, Indian Institute of Technology, Roorkee 247667, India
}

\begin{abstract}
Authors have conducted experiments to measure blast induced rock mass damage at L\&T-(Singoli-Bhatwari Hydro-Power Project SBHP) Rudraprayag. Repetitive NX size rock core up to $5.0 \mathrm{~m}$ depth were taken from side wall and face with triple tube core barrel drill. CR (core recovery) and RQD (rock quality designation) of the rock cores is computed to evaluate effect of blasting on the surrounding rock mass. RQD and CR values for the initial one meter from the line of excavation in each case reflect maximum damage due to blast. RQD for initial one meter reduced to as high as $40 \%$ of the average RQD. The rock samples were also tested using ultrasonic techniques. Ultrasonic tests on NX size core reveal that the $2.0 \mathrm{~m}$ of the zone surrounding the opening are adversely affected by the tunnel excavation blasting process. The ultrasonic velocities reduce to approx. $80 \%$ of the average values in the initial $0.5 \mathrm{~m}$ from the excavation line.
\end{abstract}

Key words: Blast induced damage, ultrasonic velocity, RQD and core recovery.

\section{Introduction}

In spite of various problems associated with system, drilling and blasting method of rock excavation is predominantly used worldwide due to inherent flexibility in the system, lower capital investment, etc.. Drilling and Blasting method gives good progress in favourable rock mass condition. Compatibility and feasibility to any sudden required alteration in dimension of excavation profile and/or geological constraints also adds to the popularity and suitability of the drilling and blasting method over other methods of excavation [1, 2].

Drilling and blasting invariably causes damage to the surrounding rock mass during excavation threatening the safety of structures. Blast induced rock mass damage is a matter of concern for the practicing engineer and researchers. Perimeter control and smoothwall blasting techniques have long been used

Corresponding author: Harsh Kumar Verma, Sr. Scientist, research fields: blast induced damage, blast design optimization, ground vibration and AOP Mitigation. E-mail: drharsh77@gmail.com. to control BID (blast induced damage) in excavation works. In spite of these precautionary measures, blast damage is still inevitable and the consequences are clearly evidenced in the form of increased support cost and requirements, slow tunnel advance, unforeseen stability problems originating from blast damage, conduit for water flow, reduction in tunnel life leading to performance, and functionality problem of the underground structures. Rock mass damage leads to deterioration of rock mass strength due to newly generated or extended fractures, or the opening of; and shearing along, cracks and joints due to mining induced stress or blasting. Blasting, one of the reasons for the rock mass damage, dynamically loads a rock mass that in turn may result in deterioration of the rock mass quality and in situ strength [3]. Any damage inflicted upon the rock by blasting is designated as BID. The damage problems of surrounding rock caused by blasting have caught worldwide attention for a long time [4]. Researchers have carried out a great deal of theoretical, numerical and experimental works to precisely determine BID in 
underground excavation on the basis explosive mechanics, fracture mechanics and damage mechanics. Research and development works in various aspects of drilling and blasting technology have presently facilitated the excavation engineers to have scientific implementation of this technology in excavation engineering design works [5].

Authors have carried out experiment at L\&T-SBHPP (Singoli-Bhatwari Hydro-Electric Power Project) site, Rudraprayag, Uttarakhand state, India to measure BID in the surrounding rock mass using ultrasonic techniques. Results of the ultrasonic measurement of rock core samples and a brief review on BID mechanics suggested by various researchers are presented in this paper.

\section{Blast Induced Damage-A Review}

Rock mass damage can ascribed to different processes such as inherent damage arising from tectonics or presence of discontinuities, fractures and faults of various dimensions; mining induced, i.e., from stress redistribution due to excavation and blasting [6]. Any damage inflicted upon the rock by blasting is designated as BID. The process of rock breakage by blasting, takes place by opening of tight, and loose joints and generation of new cracks. This generally occurs when the pressure pulse exceeds the dynamic compressive strength of rock. Generation of cracks takes place when the gas pressure exceeds the horizontal stress across the plane of discontinuities and extension of cracks depend on the tangential pressure induced by shock wave; reflection of shock wave from free face or joint planes; wedging action at the crack tip due to high temperature and pressure of gas energy entering the narrow radial crack tips [7-10].

Uncontrollable geo-technical parameters such as uniaxial compressive strength, joint plane spacing, joint plane orientation, joint plane aperture and filling material between joints contribute towards damage [10]. Optimization of shock and gas energy as a part blast design with proper charge parameters and initiation sequence is essential to restrict and prevent wide opening of joints. Shock wave, in general, is present only up to a distance where non-reversible energy dissipation is observed, i.e., the zone where rock medium behaves like plastic rather than elastic [11]. This is also known as Hugoniot elastic limit or crushed zone [12]. It generally weakens the strength properties of in situ rock mass up to a restricted distance from the blast borehole and depending upon blast parameters it generally varies between 2 times and 8 times the diameter of blast hole. Gas energy, on the other hand, having the capability of extending cracks to about 10-100 times more than shock energy are more dominant for extending fractures and should be optimized to prevent damage of in situ peripheral rock mass [13, 14].

The phenomenon of damage according to Holmberg and Persson [15] is a result of the induced strain $\varepsilon$, which for an elastic medium, in the sine wave approximation, is given by the equation:

$$
\varepsilon>\sigma / E>V \max / C p
$$

where, $\varepsilon=$ induced strain, $\sigma=$ stress generated, $E=$ Young's modulus, Vmax = vibration velocity, $C p=$ wave propagation velocity of the rock.

Various researchers have proposed different blast damage indices based on the field and laboratory experiments. The studies conducted by Swedish Detonic Foundation [16] resulted in a damage model, wherein damage to a rock mass is indicated if post blast cracks exceeds the pre-blast cracks. Holmberg [17] concluded that damage was inflicted mainly in the rock structural discontinuities and joints, cracks and other weak planes in the rock mass; rock mass was considered disturbed through the following mechanisms:

- Near hole crushing due to high shock wave amplitudes;

- Generation of radial cracks due to high-pressure gas in the drill hole;

- Opening of the existing joints because of 
high-pressure gases produced from detonation of explosive;

- Fractures through spalling;

- Reduction of shear strength due to blast induced rock movement;

- Vibration induced displacement affecting the local slope stability or tunnel perimeter.

A difference exists between the visible damage and the actual damage since cracks extend beyond the field of vision. The width of cracks in rock surrounding the opening may be in microns but this is enough to significantly reduce the rock mass strength. It is, therefore, necessary to identify both visible and invisible cracks. Despite several attempts to understand and quantify the damage, the near actual damage criterion is still lacking. There are no consistent methods to measure the blast-induced damage [18]. Moreover, different methods, techniques and indices are not universally acceptable due to cumbersome procedures, instrumental constraints or unsuitability to most of the rock mass conditions. Therefore, further researches to refine and simplify our understanding of the BIT and measurement techniques are required.

\section{Field Experiment}

Investigation of $\mathrm{BIT}$ in underground excavation is carried at SBHPP. Construction of 99 MW SBHPP run-of-river scheme is undertaken by L\&T-ECC (L\&T-Engineering Construction Company) at Rudraprayag district of Uttarakhand state. The project envisages construction of $11.2 \mathrm{~km}$ long, $4.9 \mathrm{~m}$ diameter, D-shaped HRT (head race tunnel) to divert water from river Mandakini. Rock cover above HRT varies from $100 \mathrm{~m}$ to $350 \mathrm{~m}$. The tunnel is aligned in a general N200E-S200W direction.

The geological map of the HRT depicts that the alignment runs through mostly colluvial terrain with intervening scanty and scattered outcrops.

Full face drilling and blasting using burn-cut is used for excavation of HRT as well as adits in the
Singoli-Bhatwari project site. Fig. 1 shows blasting pattern being followed in the HRT. Excavated area of the tunnel face is approximately $29 \mathrm{~m}^{2}$. Major portion of excavation in HRT pass through fair class of rock mass with compressive strength about $50 \mathrm{MPa}$ and Barton's rock mass quality “Q” value close to 5 . Full face blasting is adopted with $3.2 \mathrm{~m}$ hole depth and $45 \mathrm{~mm}$ hole diameter drilled using double-boom drill machine. Emulsion explosive, 80 per cent strength with non-electric initiation system is used to get average face advancement of $3.0 \mathrm{~m}$ in successive blast rounds. Total charge and MCD (maximum charge per delay) used in the optimized blast design is $140 \mathrm{~kg}$ and $20 \mathrm{~kg}$, respectively. Specific charge achieved is $1.6 \mathrm{~kg} / \mathrm{m}^{3}$. Over-break in tunnel periphery is controlled using smooth wall blasting techniques. Alternate holes are charged using low strength explosives. Burn-cut blast pattern using four $76 \mathrm{~mm}$ of reamer holes in the centre give more than $2.8 \mathrm{~m}$ of pull consistently. Use of shock tube initiation system assisted in controlling vibration and air overpressure.

\subsection{Experimental Set-up}

As sown in Fig. 2 (Section) and Fig. 3 (Plan), NX size rock core is obtained from boreholes drilled at face (A3 and A4) and side wall (A1 and A2) of HRT

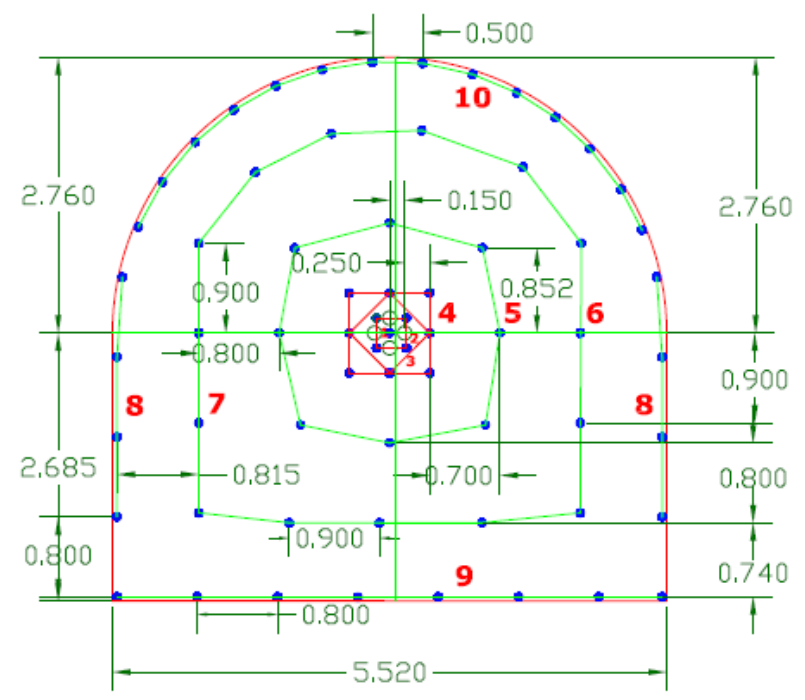

Fig. 1 Blast design for excavation of HRT. 


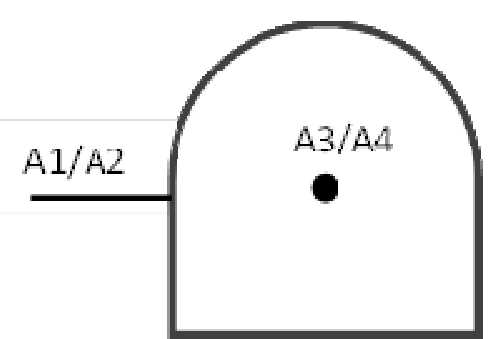

Fig. 2 Section of HRT showing coring locations.

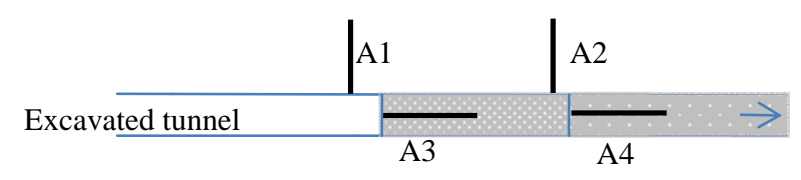

Fig. 3 Plan of HRT showing coring locations.

using triple tube core barrel. Triple tube core barrel is used to prevent damage to core while drilling as well as to improve core recovery. Core code A1 and A2 are drilled at spring level of the tunnel in the left hand side, whereas A3 and A4 are from the centre of the face. Drill depth in each location is $5.0 \mathrm{~m}$ except at A1 which was $3.5 \mathrm{~m}$ only. Table 1 give details of the core samples obtained from the HRT of SBHPP.

Fig. 4 shows NX size cores obtained from borehole A3.

\section{Results and Analysis}

\subsection{RQD (Rock Quality Designation) and CR (Core Recovery)}

The NX size rock cores obtained from the SBHPP site are logged for geological features. RQD (rock quality designation) [19] and CR (core recovery) is obtained for each coring locations. Results of the RQD values and CR are presented in Table 2. It is also important to note that the tunnel drivage direction is approximately parallel to the foliation direction of the rock mass during experimentation at A4 location. The rock found in the tunnel is quartz biotite schist.

Although, geological logging is very crude method for evaluating the BID as it is affected by direction of drilling and foliation direction of the rock mass, the values in Table 2 reveals the significant damage inflicted in the rock mass. RQD and CR values at each of the coring location are more than $70 \%$ and $90 \%$, respectively. Maximum damage due to blast occurs at
Table 1 Details of NX-size core samples.

\begin{tabular}{llll}
\hline $\begin{array}{l}\text { Coring location } \\
\text { code }\end{array}$ & Date of coring & Chainage (m) & $\begin{array}{l}\text { Length of } \\
\text { core }(\mathrm{m})\end{array}$ \\
\hline A1 & 01.04 .12 & 350 & 3.5 \\
A2 & 29.04 .12 & 358 & 5.0 \\
A3 & 01.04 .12 & 359 & 5.0 \\
A4 & 15.04 .12 & 428 & 5.0 \\
\hline
\end{tabular}

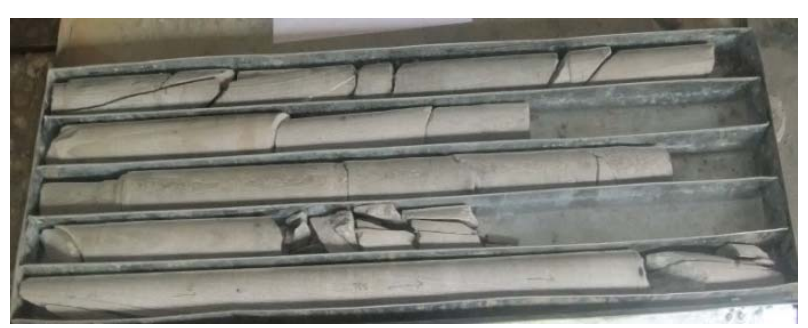

Fig. 4 NX-size core obtained at A3 (Face).

Table 2 RQD and CR values.

\begin{tabular}{lllll}
\hline \multirow{2}{*}{$\begin{array}{l}\text { Core } \\
\text { code }\end{array}$} & \multicolumn{2}{c}{ Average (\%) } & \multicolumn{2}{c}{$\begin{array}{c}\text { Values for initial one meter from } \\
\text { line of excavation (\%) }\end{array}$} \\
\cline { 2 - 5 } & RQD & CR & RQD & CR \\
\hline A1 & 89.4 & 93.9 & 61.5 & 75 \\
A2 & 95.3 & 97.3 & 75.5 & 85 \\
A3 & 69.0 & 89.8 & 62.5 & 77 \\
A4 & 72.9 & 92.8 & 33.3 & 86 \\
\hline
\end{tabular}

a closer distance and same it is reflected by the RQD and CR values for the initial one meter from the line of excavation in each case. RQD for initial one meter reduced to as high as $40 \%$ of the average RQD. Similarly, as expected, core recovery for initial one meter reduced to approximately $10 \%-15 \%$. In case of core locations A3 and A4 (Face), reduction in RQD is observed to be unusually high as the coring direction is parallel to drivage direction and perpendicular to coring.

Another important observation from geological logging at each of the four locations is that the average length of the core pieces increased rapidly as the drill depth increase. Core pieces of more than $30 \mathrm{~cm}$ are obtained beyond $2.0 \mathrm{~m}$. After $3.0 \mathrm{~m}$ from the excavation line the physical attributes of rock mass damage are absent and the core pieces of $50 \mathrm{~cm}$ and more are obtained.

\subsection{Ultrasonic Measurement}

Ultrasonic methods have been used to detect flaws in metals and concrete in past. Lustch [20] have 
carried out such studies in rocks. Blast induced rock mass damage extends pre-existing joints and cracks and also new cracks are formed. These cracks and fractures prolong the traveling route, and decreases sonic velocity through the rock mass. The decreasing degree of sonic velocity relates with the number and width of cracks and hence blasting induced damage in rock mass can be estimated, according to variance of sonic velocity.

Authors have used the "Telesonic" instrument (Roop Telesonics-India) for measurement of $\mathrm{Vp}$ (P-wave velocity) and Vs (S-wave velocity) in this experiment. The instrument consists of a double probe (separate transmitter and receiver combination) which can be moved separately on the surface. The frequency range of the transducer is between $1 \mathrm{kHz}$ and $1,000 \mathrm{kHz}$. The technique uses the indirect method of recording travel time of ultrasonic waves across a crack. Ultrasonic equipment and it is sensor used in the study, shown in Fig. 5.

The rock core samples from each of the four locations were prepared and $\mathrm{P}$-wave and S-wave velocity measurement is undertaken in the samples as per ISRM (International Society of Rock Mechanics) suggested methods [21]. Results are shown in Figs. 6-9 for coring location A1, A2, A3 and A4, respectively. Figs. 6-9 show the typical relation curves between sonic velocity and depth at different coring locations. Average $\mathrm{Vp}$ and $\mathrm{Vs}$ of the undisturbed rock mass is approx. $5,300 \mathrm{~m} / \mathrm{s}$ and $3,500 \mathrm{~m} / \mathrm{s}$, respectively. Ultrasonic velocities are also affected by confinement, mineral composition, measurement direction with respect to foliation, presence of voids, etc.. Therefore, variation upto $200 \mathrm{~m} / \mathrm{s}$ in Vp and Vs is commonly observed.

Figs. 6-9 show significant BID in the initial one meter from the line of excavation. As the depth of the cores increases the sonic velocities tends to achieve its average values. It is also observed that the maximum damage to surrounding rock mass is in the range of 0-1.0 $\mathrm{m}$ from excavation line and it reduces rapidly

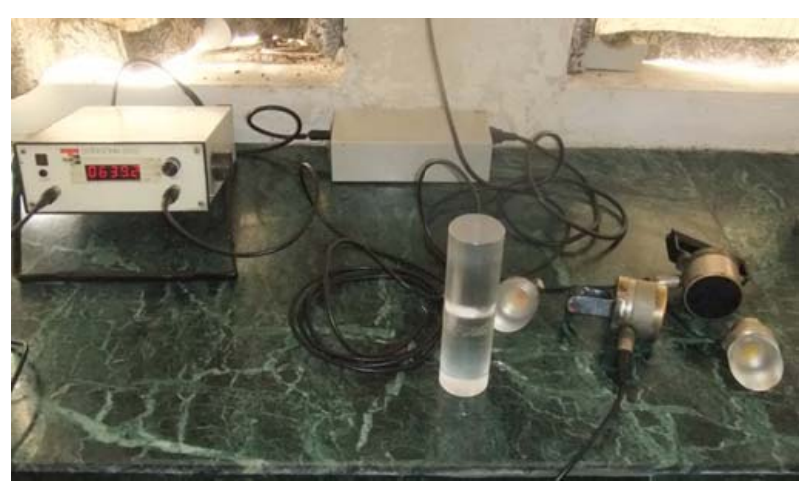

Fig. 5 Ultrasonic test equipment and sensors.

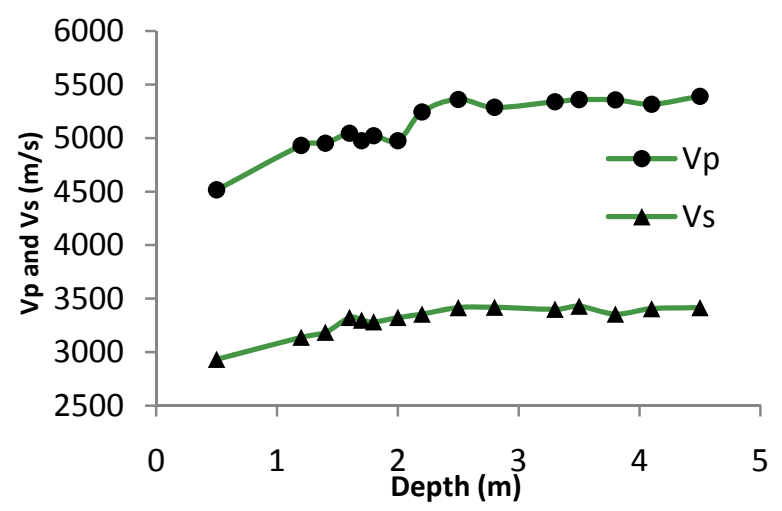

Fig. 6 Variation in Vp and Vs at A1.

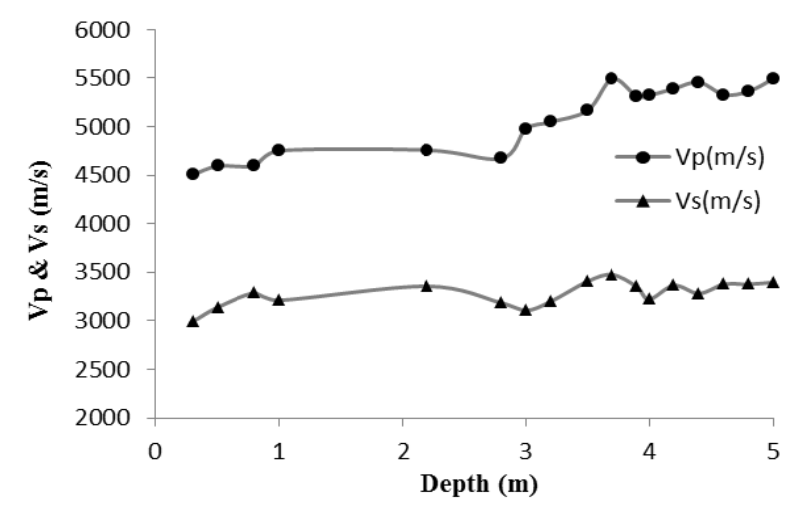

Fig. 7 Variation in Vpand Vs at A2.

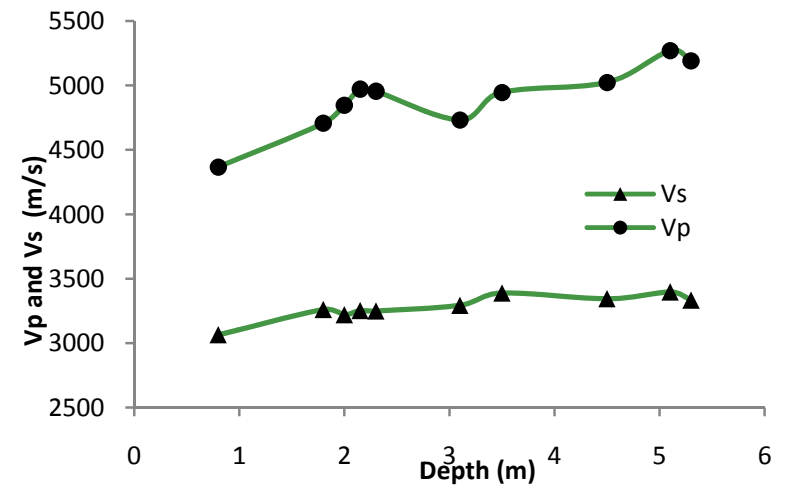

Fig. 8 Variation in Vpand Vs at A3. 


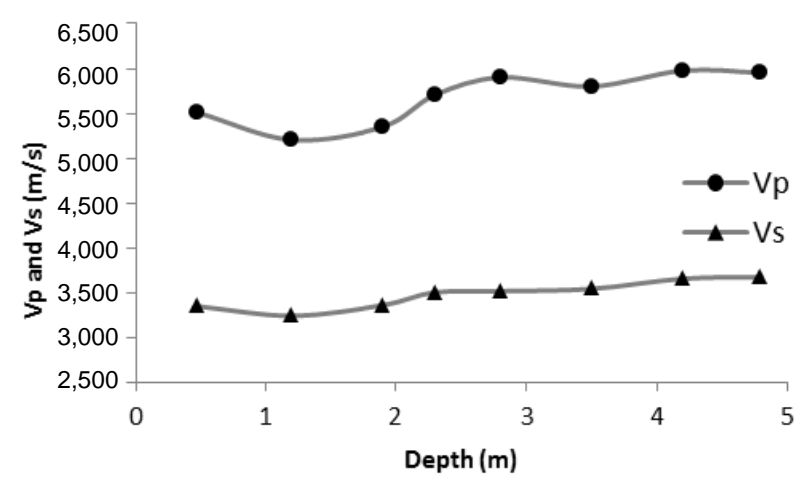

Fig. 9 Variation in Vpand Vs at A4.

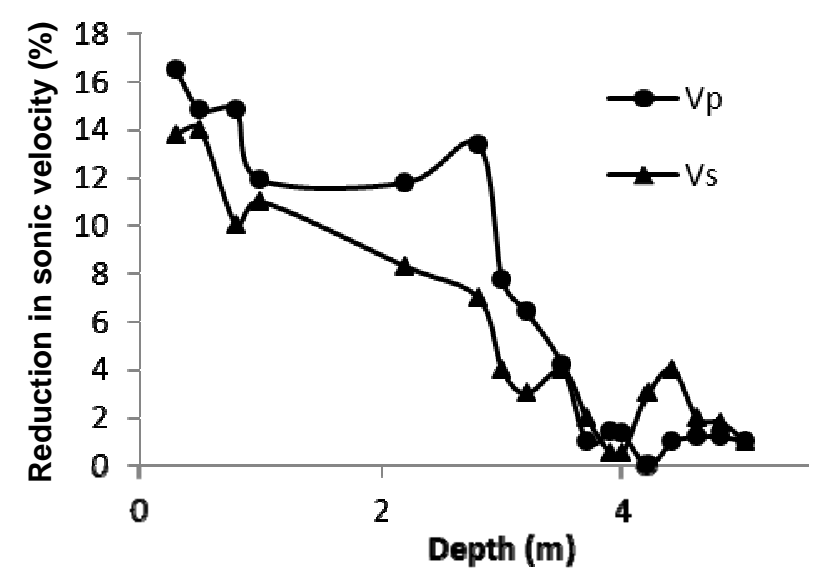

Fig. 10 Decreasing rate of sonic velocity at A4.

with distance from the blast.

Fig. 10 shows decreasing rate of sonic velocity in percentage with depth for one of the location. It is clear from Fig. 10 that there is reduction up to $16 \%$ in the sonic velocity of the rock mass in the initial half meter. Damage in the rock mass up to $2.0 \mathrm{~m}$ is significant as it reflect reduction in the ultrasonic velocity up to $10 \%$ of average values in all the locations. Beyond $2.5 \mathrm{~m}$, the reduction in the sonic velocity is less than $5.0 \%$ and it is difficult to be concluded by the ultrasonic technique. Ultrasonic technique for damage assessment may not give accurate results due to natural variation in the rock mass beyond approximately $2.5 \mathrm{~m}$ depth.

\section{Conclusions and Recommendations}

Drilling and blasting methods of excavation inevitably inflicts damage to the surrounding rock mass. Damage assessment using ultrasonic techniques reveal that there is approximately $15 \%$ reduction in ultrasonic velocity up to $1.0 \mathrm{~m}$ depth from the excavated tunnel periphery. The rock mass up to $2.0 \mathrm{~m}$ surrounding the excavation are adversely affected by the blasting process. It is difficult to characterize zone of disturbance beyond $2.0 \mathrm{~m}$ due to natural variation in ultrasonic velocity on account of the anisotropic rock mass.

Damage due to blast is reflected by the RQD and CR values. There is reduction of $10 \%-15 \%$ in RQD of values of initial one meter compare to average RQD values of the complete bore hole. This observation hold true for all the bore holes.

It is important to reduce damage to the surrounding rock mass as it adversely affects the safety and productivity of the men and machineries.

\section{Acknowledgments}

Authors express their gratefulness to Sh.V.K. Nagyan, Head, Project Implementation, Sh.K.C. Upadhyay, Co-ordinator and other officers and site engineers of L\&T-Singoli-Bhatwari Hydro-Electric Power Projects, Rudraprayag for their support in conducting this experiment successfully.

\section{References}

[1] H. Holen, A Technical Review—D\&B V Road headers, An open face choice, Tunnels \& Tunnelling International 33 (9) (2001) 45-47.

[2] H. Holen, TBM (Tunnel Boring Machine) vs. Drill \& Blast, Norwegian Tunneling Society Publication No. 11, Norway, 2002, pp. 95-98.

[3] M. Scoble, Y. Lizotte, M. Paventi, Rock mass damage from blasting: characterization and impact, In: J.A. Franklin, T. Katsabanis (Eds.), Measurement of Blast Fragmentation, CRC Press, United States, 1996, pp. 225-235.

[4] S.Q. Kou, Trend analysis of rock blasting technique from the fourth international symposium on rock fragmentation by blasting, Advances in Mechanics 24 (1) (1994) 132-135.

[5] S.K. Mandal, M.M. Singh, Evaluating extent and causes of overbreak in tunnel, Tunnelling and Underground Space Technology 24 (2009) 22-36.

[6] A.K. Raina, A.K. Chakraborty, M. Ramulu, J.L. Jethwa, Rock mass damage from underground blasting, a literature 
review, and lab- and full scale tests to estimate crack depth by ultrasonic method, Fragblast, International Journal for Blasting and Fragmentation 4 (2) (2000) 103-125.

[7] Q. Liu, P.D. Katsabanis, A theoretical approach to the stress waves around a borehole and their effect on rock crushing, in: Proceedings of the Fourth International Symposium on Rock Fragmentation by Blasting, Montreal, Canada, 1993, pp. 9-16.

[8] S.M. Tariq, P.N. Worsey, An investigation into the effect of varying joint aperture and nature of surface on pre-splitting, in: Proceedings of 12th Symposium on Explosive and Blasting Research, Orlando, 1996, pp. 186-195.

[9] P. Worsey, S. Qu, Effect of joint separation and filling on presplit blasting, in: Proceedings of the Third Mini Symposium on Explosive and Blasting Research, Miami, USA, 1987, pp. 26-40.

[10] P. Worsey, I.W. Farmer, G.D. Matheson, The mechanics of presplitting in discontinuous rock, in: Proceedings of the 22nd US Rock Mechanics Symposium U.O., Missouri, Rolla, USA, 1981, pp. 205-210.

[11] M. Olsson, I. Bergqvist, Crack lengths from explosive in multiple hole blasting, in: Proceedings of the Fifth International Symposium on Rock Fragmentation by Blasting, Balkema, Rotterdam, 1996, pp. 187-191.

[12] M. Olsson, S. Nie, I. Berqgvist, F. Ouchterlony, What causes cracks in rock blasting, in: Proceedings of Intl. Conf. Rock Fragmentation by Blasting, Fragblast, 2002, pp. 221-233.

[13] P.S.B. Colback, B.L. Wild, The influence of moisture content on the compressive strength of rock, in: Proceedings of the Third Canadian Rock Mech.
Symposium, Toronto, 1965, pp. 65-83.

[14] A. Dachnke, H.P. Rossmanith, R.E. Knasmiller, Blast-induced dynamic fracture propagation, in: Mohanty (Ed.), Rock Fragmentation by Blasting, FRAGBLAST V, Rotterdam, 1996, pp. 13-18.

[15] R. Holmberg, P.A. Persson, Design of tunnel perimeter blasthole patterns to prevent rock damage, Trans. Inst. Min. Metall (Sect. A: Min. Ind.), 1980, A37-40.

[16] R. Holmberg, P.A. Persson. The Swedish approach to contour blasting, in: Proceedings of the IVth Conf. on Exp. and Blasting Tech. ISEE, New Orleans, LA, 1978, pp.113-127.

[17] R. Holmberg, Recent developments in control rock damage, In: Rossmanith, H. P. (Ed.), Rock Fragmentation by Blasting, 1993, pp. 197-198.

[18] R.L. Yang, W.F. Bawden, S. Talebi, P. Rocque, Blast damage study by measurement of blast vibration and damage in the area adjacent to blast hole, in: H.P. Rossmanith (Ed.), Proceedings of Fourth International seminar on Rock Fragmentation by Blasting, FRAGBLAST-4, Vienna, Austria, 1993, pp. 137-144.

[19] D.U. Deere, Geological consideration, in: R.G. Stagg, D.C. Zienkiewicz (Eds.), Rock Mechanics in Engineering Practices, Wiley, New York, 1968, pp. 1-20.

[20] A. Lustch, The experimental determination of the extent and degree of fracture of rock faces by means of an ultrasonic pulse reflection method, Journal of the Southern African Institute of Mining and Metallurgy 59 (8) (1959) 412-429.

[21] ISRM Suggested Methods for Measurement of Sound Velocity in Rock, ISRM (International Society of Rock Mechanics), 1978. 